\title{
¿Qué queda de la Ilustración? Apuntes para un debate ${ }^{1}$
}

What's left of the Enlightenment? Notes for a debate

\author{
José Manuel Romero Cuevas
}

Universidad de Alcalá de Henares

\begin{abstract}
RESUMEN. El presente artículo pretende ser una aportación a la discusión sobre el significado y el contenido de verdad para nosotros del concepto de Ilustración. Se hace cargo de las críticas que la Ilustración ha recibido históricamente desde diferentes frentes, reflexionando sobre si afectan al núcleo normativo de la misma. Se propone, además, aportar ideas para repensar la validez de este núcleo normativo para las coordenadas de nuestro paradójico mundo, en el que se confrontan una globalización con caracteres imperialistas y un pluralismo reflexivo que cuestiona el etnocentrismo occidental.
\end{abstract}

Palabras clave: Ilustración, filosofía política, progreso, racionalidad.
ABSTRACT. The present article is a contribution to the discussion about the significance and the content of truth we confer to the concept of Enlightenment. It covers the most important critiques that the Enlightenment has historically received from different sides and reflects about whether these affect its normative core. Besides, it wants to show the necessity of rethinking the validity of this normative core for the coordinates of our paradoxical world, in which a globalization said to have imperialist features confronts a reflexive pluralism which questions western ethnocentrism.

Key words: Enlightenment, Political Philosophy, Progress, Rationality.

La pretensión de explicitar el posible contenido de verdad para nosotros de ese movimiento intelectual y cultural que fue la Ilustración del siglo XVIII se enfrenta en nuestra época con significativas resistencias que han arraigado y se han extendido en los planos teórico y político. Tal pretensión parece arriesgarse en nuestros días a recibir descalificaciones análogas a esas otras devenidas típicas del campo filosófico, como son las de realismo ingenuo o materialismo burdo. La reivindicación como válida de alguna dimensión de la Ilustración parece atentar contra determinadas supuestas evidencias de nues-

1 Este trabajo forma parte del proyecto de investigación HUM2007-61018 del Ministerio de Educación y Ciencia. Agradezco a Eduardo González Di Pierro y Miguel Ángel Urrego su invitación para exponer estas ideas en el marco del Diplomado sobre Filosofía de la Historia coordinado por ellos en la Facultad de Filosofía de la Universidad Michoacana de Morelia (México) y a Carlos Bustamante, profesor de esta Facultad, su interés en verlas plasmadas por escrito. 
tro tiempo en torno a la crisis, superación o simplemente fin de la Ilustración (evidencias que afectan asimismo al propio concepto de modernidad) y haberse quedado anquilosada en un tiempo anterior a la irrupción de los discursos post (postmodernismo, poshistoria, posmarxismo...), sobre todo, a partir de los años 70 del siglo XX.

Para evitar que estas observaciones sobre la Ilustración reciban de principio y precipitadamente descalificaciones por ingenuas o burdas, al no tener en cuenta los avatares sufridos por tal concepto en el pasado reciente y no tan reciente, voy a comenzar enumerando y valorando algunas de las críticas más importantes realizadas con anterioridad y en la actualidad a tal movimiento intelectual y sociohistórico. La exposición de estas críticas permitirá hacer referencia a toda una serie de tópicos dominantes en la sensibilidad histórica de nuestro tiempo, lo que atemáticamente constituiría lo que podríamos llamar el sentido común de nuestra época. Esta remisión es necesaria para evitar que esta aportación a la discusión caiga en la mera presentación de buenos deseos e intenciones o en la pura abstracción, desconectados ambos del horizonte histórico que debería sustentar todo intento de reflexión. Pretende referir muy someramente algunos niveles de significado que el concepto de Ilustración ha recibido en el pasado y que mediatiza necesariamente nuestra relación con el mismo en el presente. Lo que tratamos de valorar, naturalmente sin poder profundizar pormenorizadamente en ello, es si hacen justicia a lo que podríamos identificar como lógica profunda de la Ilustración. Enumeremos, pues, algunas de las objeciones que la Ilustración ha recibido y continúa recibiendo:

a) La Ilustración ha sido cuestionada desde diversos frentes por ser una ideología del progreso ${ }^{2}$. Se le ha reprochado una fe (por definición, no razonada) en que el proceso histórico, a pesar de no estar orientado por ninguna decisión colectivamente acordada y planeada, está impulsado por una lógica, por una dinámica propia, que conduce a un mejoramiento y perfeccionamiento en todos los niveles de la existencia social, desde la ciencia natural y la técnica hasta incluso la política y la moral. El progreso es pensado aquí como la dinámica esencial a la historia, sobre todo en los tiempos modernos, que se impone a espaldas de los sujetos e impulsa a través de su práctica social individual, monológicamente orientada, un avance en todos los órdenes de la vida. Al ser considerado como proceso que actúa a espaldas de los sujetos, la justificación del progreso acudió en importantes representantes del pensamiento moderno a un

2 Quizá la crítica más poderosa a la ideología del progreso fue la realizada por W. Benjamin en su obra madura. Ver especialmente su Libro de los Pasajes, Madrid, Akal, 2005, y sus «Tesis sobre el concepto de historia», publicadas en su momento en W. Benjamin, Discursos interrumpidos I, Madrid, Taurus, 1973, pp. 177-191, y ahora editadas en W. Benjamin, Obras, Libro I, vol. 2, Madrid, Abada, 2008, pp. 305-318. Una exposición de los argumentos críticos que se oponen en la actualidad a la filosofía ilustrada de la historia aparece en A. Gómez Ramos, Reivindicación del centauro. Actualidad de la filosofía de la historia. Madrid, Akal, 2005, pp. 7 y ss. 
ingenioso mecanismo teórico ya utilizado por los pensadores estoicos para sustentar el carácter racional de la totalidad, en su caso, del cosmos. ${ }^{3}$ Este mecanismo de legitimación se sostiene en la distinción entre las perspectivas de lo singular y lo universal para privilegiar la segunda como normativa. Esto se traduciría en la tesis según la cual lo que desde la perspectiva individual aparece como sufrimiento y mal sin sentido debe ser considerado como cumpliendo un papel positivo y productivo en el orden de lo universal. El mal es considerado así pura apariencia. Aparece a causa del carácter finito y limitado de una perspectiva, la individual, incapaz de comprender la racionalidad y sentido del todo. Tal perspectiva debería ser trascendida, a partir de una especie de salto mortal, hacia la asunción de la perspectiva de lo universal, donde la apariencia de mal es transubstancializada en constatación de su carácter de bien para la totalidad. La aplicación de esta argucia al plano de la historia permitió una legitimación de la ideología del progreso, como se comprueba en la obra de Mandeville, Smith, Kant y Hegel (y en la de ese ilustrado hegeliano que fue Marx, para el cual la historia avanza por el lado malo) ${ }^{4}$, según la cual lo que desde la perspectiva subjetiva moral es un mal (la orientación por el propio egoísmo, la insolidaridad, el antagonismo de intereses y clases) actúa efectivamente como motor del avance histórico hacia cotas mayores de perfección y desarrollo social, de racionalidad y moralidad.

Considero que esta crítica a la Ilustración es acertada y apunta a una de sus señas de identidad más propias. Su objetivo es denunciar la idolatrización de la historia acontecida como plena de sentido y la divinización del presente en su forma dada, en tanto que fruto maduro y culminación significativa de la racionalidad del proceso que conduce a él. Esto posee un carácter legitimador del presente histórico que lo inmuniza respecto de toda crítica y todo intento de transformación, como supieron ver desde paradigmas filosóficos diferentes Nietzsche y Benjamin. El primero sostuvo de manera polémica: «para Hegel el punto culminante y el punto final del proceso del universo coincidían en su propia existencia berlinesa. Mirándolo bien, Hegel hasta tendría que haber dicho que todas las cosas posteriores a él habrían de valorarse como una mera coda musical del rondó histórico universal, más propiamente, como una superficialidad. No decía esto: en cambio ha inculcado en las generaciones imbuidas de ese modo de pensar esa admiración por el «poder de la Historia» que, de hecho, se trueca a cada instante en admiración descarada por el éxito y lleva al fetichismo del hecho consumado: fetichismo para el cual se ha introducido ahora esta consigna muy mito-

3 Ver Roberto R. Aramayo, «El «utopismo ucrónico» de la reflexión kantiana sobre la historia», en I. Kant, Ideas para una historia universal en clave cosmopolita, Madrid, Tecnos, 1987, pp. IX-LXIV (cf. Critica de la razón ucrónica, Tecnos, Madrid, 1992, pp. 119-248), y Concha Roldán, Entre Casandra y Clío. Una historia de la filosofía de la historia, Madrid, Akal, 2005, pp. 83 y ss.

4 Ver É. Balibar, La filosofía de Marx, Buenos Aires, Nueva Visión, 2000, pp. 108 y ss. 
lógica y auténticamente alemana: «Amoldarse a los hechos» [Thatsachen]. Pero quien ha aprendido a doblar la espalda y a agachar la cabeza ante el «poder de la Historia» termina por asentir con la cabeza, en un gesto maquinal-chinesco, ante cualquier poder, ya sea un gobierno o una opinión pública, o bien una mayoría numérica, moviendo sus miembros exactamente al compás al que algún «poder» tira del hilo. Si todo éxito conlleva una necesidad racional, si todo suceso significa el triunfo de lo lógico o de la «idea» - entonces $j$ a ponerse de rodillas y recorrer arrodillado toda la escala de los «éxitos»!» ${ }^{5}$ Si la categoría moderna de progreso conduce a colocarnos como observadores sumisos y fatalistas ante un acontecer que se presenta con necesidad y plena justificación, resulta claro que todo cuestionamiento de lo existente que se pretenda radical debe tener como punto de partida la aniquilación de la noción de progreso tal como es pensada por la Ilustración y la filosofía moderna, capaz de conferir sentido y significatividad al más oscuro de los presentes, como lo demuestra tanto la historia de las sociedades capitalistas como las denominadas del socialismo real ${ }^{6}$.

b) La Ilustración habría promovido una experiencia del tiempo en la que lo relevante es la orientación hacia un porvenir, que la fe en el progreso caracteriza como mejor que el presente, y el distanciamiento respecto de un pasado percibido como contaminado por todo aquello de lo que el ilustrado quiere separarse: oscurantismo, superstición, ignorancia, irracionalidad... Esta orientación hacia el futuro, del que nos cabe esperar una mejora no sólo de las condiciones de vida, sino de la misma humanidad, determina una actitud hacia el pasado como rémora de la que hemos de liberarnos, dejándola definitivamente atrás. Esta devaluación ilustrada del pasado se habría acompañado de un descuido y un olvido más o menos activo. La actitud ilustrada podría sintetizarse en el lema: "para progresar hay que mirar al futuro, no al pasado». Esto ha sido cuestionado como una consagración de la anulación de la posibilidad de una experiencia moral del pasado relevante para los agentes actuales embarcados en un proceso de enfrentamiento con las injusticias existentes. La Ilustración conduciría a una desproblematización moral del pasado, eliminando con ello una dimensión central de la vida moral del colectivo social, a saber, el modo en que se relaciona y se ajustan cuentas con el sufrimiento de las víctimas del proceso histórico que ha acabado imponiéndose como válido e incuestionable en nuestro presente. El empobrecimiento de esta dimensión moral conduce a su vez a una degradación de la acción social en el presente, que da por bueno el estado de cosas existente al no tener en cuenta la posibili-

5 Ver F. Nietzsche, Sobre la utilidad y el perjuicio de la historia para la vida, Madrid, Biblioteca Nueva, 1999. Ver además W. Benjamin, «Tesis sobre el concepto de historia».

6 Una contundente crítica de la ideología del progreso presente tanto en el liberalismo como en el socialismo real es realizada en F. Hinkelammert, Crítica de la razón utópica, Bilbao, Desclée de Brouwer, 2002. 
dad de una sociedad diferente encarnada en los proyectos y sueños frustrados de los vencidos en el pasado ${ }^{7}$.

c) Otro aspecto de la Ilustración muy denunciado es su carácter etnocéntrico, su adopción de la cultura europea como normativa y como fuente originaria del proceso de Ilustración. El horizonte claramente eurocéntrico de un pensador defensor de la modernidad como es el caso de Habermas se pone de manifiesto en la pregunta con la que cierra sus conferencias sobre el discurso filosófico moderno: «¿quién otro sino Europa podría sacar de sus propias tradiciones la penetración, la energía, la voluntad de visión y fantasía - todo aquello que sería menester para quitar su fuerza configuradora de mentalidades a las premisas, desde hace ya mucho tiempo no metafísicas sino metabiológicas, de esta enceguecida compulsión a mantener y seguir expandiendo el sistema?» ${ }^{8}$. Esto constituiría otra dimensión cuestionable de la Ilustración, pues la consideración de que la cultura europea occidental (y para muchos esa expresión refiere esencialmente una cultura cristiana) es la matriz de la Ilustración confiere a Europa y Occidente en general una posición privilegiada a nivel mundial en relación al impulso de un progreso científico, material, moral y civilizatorio en todo el globo. Se podría entender el uso del discurso ilustrado en los siglos XIX y XX por los países occidentales como una forma de autojustificación frente a los demás (en vías de civilización/ilustración) de tal posición priviliegiada. Este discurso etnocéntrico ha devenido (y deviene) con mucha facilidad una forma de discurso colonial e incluso imperialista que reivindica para Occidente la tarea de extender y expandir las luces, la razón, la libertad, por las regiones del globo aún no ilustradas-civilizadas. La Ilustración legitimaría así en términos filosóficos y morales la expansión colonial de Europa como proceso civilizador, en el que se dan la mano la extensión de la razón y la expansión de los productos manufacturados de la metrópoli: ambas respaldadas por el uso de una violencia legitimada en nombre de la civilización (ni siquiera Marx fue del todo ajeno a este modo de ver las cosas).

A pesar de la fuerza de esta crítica, no creo que afecte a lo que quisiera denominar aquí como núcleo de la Ilustración. Pues, históricamente, a pesar de que efectivamente la cuna de la Ilustración fue Europa (más bien una región determinada de la misma), ya a finales del siglo XVIII se desarrollaron esfuerzos ilustradores más radicales y consecuentes que en la metrópoli en otras regiones del globo, por ejemplo en Latinoamérica. Aquí la Ilustración llegó a tomar la forma significativa de una lucha contra el colonialismo a favor, no sólo de la ruptura de las cadenas de sometimiento colonial sino, además, de la liberación de las relaciones de servidumbre y esclavitud raciales impuestas por las metrópolis, como se patentizó ejemplarmente en el caso de

7 Ésta es una de las tesis centrales de R. Mate, Medianoche en la historia. Comentarios a las tesis de Walter Benjamin "Sobre el concepto de historia», Madrid, Trotta, 2006.

8 J. Habermas, El discurso filosófico de la modernidad, Madrid, Taurus, 1989, p. 433. 
Haití ${ }^{9}$. Esto permite sostener que la Ilustración no es monopolio europeo ni occidental y poner de manifiesto además que su lógica profunda (que voy a tratar de determinar más adelante) puede llegar a cuestionar lo que la crítica aquí mencionada había atribuido a la Ilustración como tal: su etnocentrismo occidental y su connivencia con el colonialismo. El caso de Latinoamérica demuestra que esos caracteres son espurios y que cabe pensar formas de Ilustración liberados de ellos, es decir, formas de Ilustración, ubicadas geográfica y culturalmente fuera de los centros de poder geopolíticos, capaces de definir, también contra éstos, una senda propia de emancipación en la que ideas críticas forjadas en la metrópoli son leídas, reinterpretadas y cuestionadas tanto desde las condiciones materiales y culturales autóctonas como de las convicciones morales arraigadas en las formas autóctonas de vida.

d) Se ha problematizado además el hecho de que la Ilustración persiguiera explícitamente la instauración del ser humano como señor y dominador de la naturaleza a través de la ciencia, la técnica y la industria, pues habría posicionado al hombre moderno en una relación con la naturaleza definida por el expolio y la pura dominación ${ }^{10}$. En este punto, lo que habría hecho paradigmáticamente la Ilustración es proseguir de forma secularizada esa idea defendida por el cristianismo acerca de que la naturaleza ha sido creada por Dios y puesta ahí para disfrute y usufructo del hombre. Ahora bien, la Ilustración habría proseguido esta idea con nuevos medios, pues lo propio de la misma fue tomar constancia del significado antropológico del nuevo poder representado por la ciencia y la técnica modernas. ${ }^{11}$ En esta orientación de la Ilustración hacia la dominación de la naturaleza arraigaría lo que se ha considerado su concepción de la razón: una concepción reductiva de la misma como razón instrumental. Es decir, la Ilustración habría concebido la razón a partir del modelo representado por la actividad de manipulación, control y transformación técnicos de la realidad natural. El núcleo de la razón sería pues la dominación y la aplicación de tal concepción de la racionalidad a la sociedad en forma de conocimiento científico o racionalización social habría tenido en consecuencia efectos fundamentalmente cosificadores ${ }^{12}$.

Resulta claro que la Ilustración en general careció de una reflexión adecuada acerca de la relación práctica entre ser humano y naturaleza y que consideró evidente que tal relación cabía ser pensada en términos de dominación. A pesar de ello, lo cierto es que esta concepción de la relación hombre-naturaleza convivió en algunos ilustrados, como Diderot, Rousseau y el propio

9 S. Buck-Morss, «Hegel y Haití», Revista Casa de las Américas, La Habana, Casa de las Américas, 2006, n. ${ }^{\circ}$ 242, pp. 36-58.

10 Ver M. Horkheimer y Th. W. Adorno, Dialéctica de la Ilustración, Madrid, Trotta, Madrid, 1997.

11 Sobre esto ver R. Koselleck, Aceleración, prognosis y secularización, Valencia, Pretextos, 2003.

12 Cf. M. Horkheimer, Crítica de la razón instrumental, Madrid, Trotta, 1999. 
Kant (por no mentar a autores no ubicables en la corriente de la Ilustración histórica del siglo XVIII, pero de significado central en la filosofía moderna, como Spinoza o Schelling), con la defensa, en términos artísticos o filosófi$\cos$, de una experiencia de la naturaleza que no la reduce a objeto de instrumentalización, sino que es capaz de aprehenderla como realidad poseedora de un carácter estético propio (es decir, la naturaleza como prototipo de lo bello y lo artístico), o bien como realidad viva, activa, dinámica, que transciende su percepción como mero correlato pasivo del conocimiento y el trabajo humanos (aunque hay que afirmar que estas dos posibilidades no son excluyentes, sino que en el planteamiento de diversos autores modernos han ido de la mano). Es decir, nos encontraríamos en el seno de la misma Ilustración con una diversidad de posiciones respecto a la concepción de la naturaleza y de la relación del hombre con ella. Lo importante aquí es plantearse por qué una de las posiciones alcanzó primacía y fue realizada dominantemente en el ámbito social mientras que la otra quedó desactivada y relegada en forma de experiencia estética o incluso mística (que, como se sabe, dejan todo tal como está). Pero tal cuestión nos traslada, desde una problematización de la Ilustración como tal, hacia la temática del tipo de realización de la misma que se ha efectuado en la historia moderna y contemporánea, la cual apunta consecuentemente a condiciones y factores históricos que puede afirmarse que no afectan al núcleo de contenido definitorio y normativo de ese movimiento intelectual que es la Ilustración.

En todo caso, podría aceptarse que efectivamente este problema de la dominación de la naturaleza a través de la técnica y la industria es un punto ciego de la corriente dominante de la Ilustración, en el sentido de que los teóricos ilustrados más influyentes no cuestionaron tal dominación (aunque investigaron las virtualidades de otras formas de experiencia no dominantes de la naturaleza). Lo que hay que plantearse es si este acriticismo se sustenta en, llamémosla así, la esencia de la Ilustración o si ella misma exigiría (y habría exigido) en coherencia con sus principios hacer reflexiva esta dimensión no tematizada. Cuando hablo aquí de los principios de la Ilustración estoy haciendo referencia a sus fundamentos racionales, tal como se encuentran explícitamente en autores como Rousseau o Kant, para los cuales la razón no se reduce a razón instrumental sino que incluye una dimensión práctico-moral sustentada en el plano intersubjetivo y una pretensión autorreflexiva, la cual es central también en otros relevantes pensadores modernos. A partir de tal pretensión de autorreflexión de la razón ilustrada, ¿puede exigírsele al propio proceso de Ilustración, como pretendieron Adorno y Horkheimer, que reflexione sobre esa opacidad y ese mito presente en ella sin que sea necesario recusar el proceso en su totalidad? ${ }^{13}$ Lo que aquí se exigiría es una pertinente Ilustración de la Ilustración, en la que ésta vuelva contra sí misma, contra su

13 M. Horkheimer y Th. W. Adorno, Dialéctica de la Ilustración, ed. cit., pp. 93 y ss. 
realización histórica concreta, deudora de las evidencias e intereses sociales dominantes en su tiempo, el aguijón crítico de esa reflexión racional que fue elevada por ella a instancia suprema.

e) Desde algunas posiciones se ha denunciado el carácter burgués de la Ilustración, a saber, el hecho de que proyectó un mundo que coincidía en sus límites con la sociedad burguesa moderna. En consecuencia, su pretensión de emancipación se reduciría a la liberación respecto a las asimetrías no razonables (basadas en el estamento, la procedencia, en la sangre) del Antiguo Régimen, pero dejaría incólumes las asimetrías razonables (basadas en el mérito y el éxito) generadas por (y sustentadoras de) la sociedad burguesa. La Ilustración habría sido el movimiento político-intelectual de la burguesía ascendente contra el orden social y cultural caduco que parasitaba una vida social burguesa pujante que aspiraba a liberarse. Por ello, todos los ilustrados y las constituciones políticas revolucionarias hijas de la Ilustración defendieron el derecho a la propiedad privada como derecho fundamental de los ciudadanos. Toda esta caracterización conduciría a cuestionar que la Ilustración pueda aportar algo productivo a la crítica de las desigualdades generadas por la sociedad capitalista, por lo que tal crítica debe buscar su apoyo en otros parajes teóricos, dejando como improductiva a tal tradición. Esta línea de argumentación conduciría a sustentar las pretensiones de cierto postmodernismo de izquierdas.

Creo que esta crítica tiene su fundamento, pero se toma quizá demasiado en serio la forma que tomó de hecho la filosofía y la práctica políticas de los ilustrados en perjuicio del significado propio del proyecto ilustrado, sin plantear adecuadamente si esa concreción de la posición política de los ilustrados se deriva de tal significado propio de la Ilustración, o si se trata de un rasgo que remite al modo en que sus representantes se dejaron llevar por los prejuicios y expectativas características de su posición de clase social. El hecho de que en plena revolución francesa se produjera un intento revolucionario igualitarista que cuestionaba la propiedad privada de las fuentes de riqueza (el caso de Babeuf), ilumina quizá la dirección de una posible radicalización de la Ilustración histórica hacia la explicitación y realización de su lógica profunda, la cual no puede contentarse con dar por buenos presuntos derechos fundamentales del hombre que, ni pueden ser apropiados por los muchos, ni permiten que sea superada la situación de sometimiento material de los de abajo. Se definiría así una dirección en la que efectivamente Marx aparecería, en este punto concreto, como ilustrado perfectamente consecuente. En esta dirección apunta la historización de I. Ellacuría del modo ideologizado de concebir los derechos humanos, el cual consiste en pensarlos como derechos cuya defensa y afirmación no tiene por qué ocuparse de las condiciones de su realización en una sociedad marcada por la desigualdad y el conflicto. Ese modo de concebir los derechos humanos conduciría a invisibilizar lo que constituye la tarea pendiente de las sociedades democráticas modernas: la instauración de las condiciones que po- 
sibilitarían la apropiación universal de tales derechos, la cual implicaría una subversión del orden de cosas moderno-burgués ${ }^{14}$.

f) De una forma ciertamente polémica, también se le podría reprochar a la Ilustración su problemática actitud frente a la democracia. Pues, paradójicamente, los alegatos a favor de la soberanía popular en el plano político fueron de la mano frecuentemente de una visión restrictiva de la aplicación de la democracia representativa. De hecho, importantes figuras de la Ilustración optaron por formas más o menos refinadas de despotismo ilustrado, pues la constatación común fue que el juicio político del pueblo aún no estaba lo suficientemente preparado y madurado como para hacerlo capaz de decidir racionalmente en la esfera pública. Por ello, y mientras eso sucedía, es decir, mientras se producía esa salida de la autoculpable minoría de edad de los individuos en la que según Kant consiste la Ilustración, el poder debía ser gestionado por el monarca ganado por el filósofo a la causa ilustrada. ${ }^{15} \mathrm{Se}$ ha querido ver aquí un carácter paternalista e incluso autoritario de la Ilustración, que confiere al ilustrado una posición privilegiada a la hora de saber mejor que el pueblo cuáles son sus intereses objetivos.

A la Ilustración se le podría reprochar lo que a toda vanguardia: al colocarse por delante (es decir, por encima) de la perspectiva común, acaba adoptando para sí el ideal platónico del filósofo-rey, o sea, la posición del sujeto-que-sabe, respecto al cual los todavía rezagados, los todavía inmaduros, sólo pueden aguardar pasivamente la indicación de cuál es la dirección correcta a seguir. Aquí, como respecto a las otras cuestiones planteadas arriba, habría que reflexionar si este problema afecta al propio núcleo de la Ilustración, para lo cual tendré que enfrentar por fin el intento de definición del mismo.

Soy consciente de que dejo sin tratar otros importantes cuestionamientos de aspectos relevantes de la Ilustración, como su relación con la religión o con la ciencia, pero prefiero no ampliar demasiado el número de temas a tratar para no dispersar en exceso la argumentación. Así que una vez consideradas algunas de las principales críticas que se han dirigido a la Ilustración y apuntando el modo en que cabe hacerse cargo de ellas, voy a referir lo que considero el núcleo profundo (o, si se prefiere, el núcleo duro) de la Ilustración, donde reside la dimensión de su posible vigencia para nosotros. Naturalmente que podría defender aquí la original concepción de la Ilustración del último Foucault, para el cual lo propio de ésta sería el ser una reflexión crítica que toma como objeto a la propia actualidad ${ }^{16}$. Se podría definir a la Ilustra-

14 Ver I. Ellacuría, «Historización del bien común y de los derechos humanos en una sociedad dividida» e «Historización de los derechos humanos desde los pueblos oprimidos y las mayorías populares», en I. Ellacuría, Escritos filosóficos III, San Salvador, UCA Editores, 2001, pp. 207-225 y 433-445.

15 Cfr. I. Kant, ¿Qué es la Ilustración?, Madrid, Alianza, 2004, pp. 81-118.

16 M. Foucault, «QQué es Ilustración?», en M. Foucault, Estética, ética y hermenéutica, Barcelona, Paidós, 1999, pp. 335-352. 
ción como una problematización del tiempo presente, de sus límites, de su presunta necesidad y naturalidad. La Ilustración (sobre todo en Kant) sería la primera forma reflexiva de ontología del presente, que afronta la problemática fundamental que define a la propia coyuntura histórica en relación a las cuestiones ético-políticas centrales para los agentes actuales. La versión que Jameson da de la ontología del presente define claramente toda una tarea para el pensamiento crítico, a saber, la combinación de la determinación de «las tendencias utópicas [del presente] con una geografía benjaminiana de sus fuentes y una estimación de su presión en lo que hoy son múltiples niveles del mar» ${ }^{17}$. Es decir, la ontología del presente efectuaría una analítica histórica de las posibilidades de un mundo más justo generadas por la propia época, tanto en la dimensión del desarrollo técnico-productivo como en la de las expectativas y deseos colectivos (sobre todo, ese deseo llamado utopía rastreado por Jameson en las producciones de la cultura de masas) ${ }^{18}$. Como es sabido, el último Foucault orientó esa problematización del presente, en la que según él consiste la Ilustración, hacia una problematización de nosotros mismos, de la forma de identidad constituida históricamente que se ha acabado consolidando y coagulando como nuestra presunta esencia inmodificable, poniendo de manifiesto los límites que establece a la libertad, el modo en que nos fija en una posición restrictiva de sujeto. La Ilustración toma la forma así de una arqueología de nuestra forma de identidad que disuelva su apariencia natural y necesaria ${ }^{19}$.

Pero para la presente argumentación considero más productivo acogerme a una definición más tradicional y convencional de Ilustración: voy a considerarla en esencia como un proyecto de autoemancipación colectiva impulsado por la noción de autodeterminación racional del ser humano. En la Ilustración habría devenido reflexivo el anhelo de emancipación, por una parte, respecto de lo viejo no razonable que sigue imponiendo su poder sobre un presente que se va mostrando cada vez más como capaz de tomar un camino racional y libremente elegido. En ella habría devenido reflexivo, además, el impulso de emancipación respecto de la naturaleza (y, esto es esencial, de lo devenido naturaleza), que se impone como un destino sobre la autodeterminación colectiva y sus proyectos de construcción social ${ }^{20}$. Claro que aquí la distinción esencial es la que se da entre la liberación de la coacción de la naturaleza externa (que sólo puede pensarse en términos re-

17 F. Jameson, Una modernidad singular. Ensayo de una ontología del presente, Barcelona, Gedisa, 2004, p. 180. Lo introducido entre corchetes es aclaración mía.

18 Ver F. Jameson, Archaeologies of the Future. The Desire Called Utopia and Other Science Fictions, Londres/Nueva York, Verso, 2007.

19 M. Foucault, «¿Qué es Ilustración?», en op. cit., pp. 347 y ss.

${ }^{20}$ La formulación más influyente del concepto crítico de segunda naturaleza se encuentra posiblemente en la obra de juventud de G. Lukács, El alma y las formas y Teoría de la novela, Barcelona, Grijalbo, 1975, pp. 328 y ss. y 417 y ss. 
lativos y que no puede considerarse como conquistable a partir de la mera dominación, sino que exige modos de relación en los que la apropiación necesaria para la supervivencia de nuestra especie pueda convivir con formas de cuidado y de respeto aún por pensar) y la emancipación del carácter de segunda naturaleza de la realidad social: si la primera es una cuestión sobre todo ecológica, que exige aceptar la impotencia última del ser humano frente a una naturaleza que siempre lo desbordará, la segunda es una cuestión política candente y abierta. Ahora bien, para que este contenido de verdad de la Ilustración que acabo de mentar pueda aspirar a tener vigencia para nosotros, se han de responder de algún modo y tener seriamente en cuenta las objeciones arriba referidas. Aquí se define una serie de tareas ineludibles para los que quieren implementar en el plano social lo que constituiría la herencia viva y no cumplida de la Ilustración. Quisiera que las tareas a las que apunto aquí no sean consideradas como una mera propuesta personal. Las expongo en tanto que tareas vivas, en marcha, en proceso de articulación en determinados movimientos sociales reales y debates actuales. Los temas que voy apuntar a continuación creo que son rastreables en los debates y las estrategias de diversos movimientos y tendencias sociales existentes orientados cada uno a su modo a diferentes formas de enfrentamiento contra la desigualdad, la depauperización, el desprecio moral y cultural y el expolio de la naturaleza. Al enumerar estas tareas quisiera hacerme eco de procesos de discusión político-social en marcha.

ad a) El contenido de verdad de la Ilustración sólo puede hacerse vigente quebrantando la ideología del progreso que la ha contaminado desde sus comienzos. Este es quizá el reto mayor al que se enfrentan los que pretenden seguir haciendo viable el núcleo de la Ilustración. Aquí la cuestión es si la crítica a la ideología del progreso puede afinarse de manera que no desemboque en una concepción de la historia que sea su mera inversión, a saber, una concepción metafísica de la historia para la cual la historia de Occidente o, en su caso, la modernidad occidental, es esencialmente decadencia o desintegración de un estado de cosas originario, que ocuparía en la argumentación una posición normativa. Otra posición posible, que me parece igualmente difícil de justificar, es la de la crítica a la modernidad occidental adoptando como punto de vista normativo lo que supuestamente se ha mantenido indemne en la periferia respecto a la agresión colonizadora de las metrópolis. ${ }^{21}$ Sabido es que tales críticas al progreso en virtud de una concepción de la historia o de la modernidad como decadencia han tenido históricamente una pretensión y un efecto claramente conservadores, a pesar de que ha adoptado también la forma de un anticapitalismo románti-

21 Sobre este posicionamiento, ver L. Villoro, «La filosofía desde la otra cara de la modernidad», en Devenires. Revista de Filosofía y de Filosofía de la Cultura, Morelia, Facultad de Filosofía de la Universidad Michoacana, 2005, n. ${ }^{\circ}$ 12, pp. 7-19. 
co ${ }^{22}$. Por lo tanto, el rechazo de la idea de progreso como carácter esencial y natural de la historia, sobre todo en su fase moderna, ¿conduce necesariamente a eliminar toda noción de progreso?, ¿o debe abrirse la posibilidad de pensar un progreso, entendido como mejoramiento de las condiciones materiales y culturales de vida de la colectividad, en tanto que fruto de la acción política consciente del colectivo social organizado? Es lo que efectivamente pensó Benjamin, ese crítico feroz de la categoría burguesa de progreso, cuando sostuvo: «Definiciones de conceptos históricos fundamentales: la catástrofe: haber desaprovechado la oportunidad; el instante crítico: el statu quo amenaza con permanecer; el progreso: la primera medida revolucionaria» ${ }^{23}$. Desde unos parámetros filosófico-políticos diferentes, el Nietzsche ilustrado afrontó la problemática del progreso en unos términos que conectan con nuestra argumentación: «los hombres pueden decidir conscientemente seguir desarrollándose hacia una nueva cultura, mientras que antes se desarrollaban inconsciente y contingentemente: ahora pueden crear mejores condiciones para el nacimiento de las personas, su alimentación, educación, instrucción, administrar económicamente la tierra en su globalidad, sopesar y engastar entre sí las fuerzas de los hombres en general. Esta nueva cultura consciente mata a la antigua, que, contemplada en su conjunto, ha conducido a una vida inconsciente de animal y planta; mata también la desconfianza hacia el progreso; éste es posible. Quiero decir: es precipitado y casi sin sentido creer que el progreso debe tener lugar necesariamente; pero ¿cómo podría negarse que es posible?» ${ }^{24} \mathrm{Si}$ la crítica de la ideología del progreso constituye una necesidad para los movimientos sociales que cuestionan el rumbo histórico imperante, la negación de toda posibilidad de un progreso concebido en los términos de Benjamin y Nietzsche sería en cambio una forma de lo que Kant denominó «terrorismo moral» ${ }^{25}$, pues conduce a una justificación del estado de cosas existente en su forma dada por la vía de la anulación de alternativas. El que esta justificación sea llevada a cabo por un asentimiento resignado o jubiloso a lo que es, no obsta para que se la considere como una forma explícita de sabotaje de los esfuerzos por desentrañar y realizar un orden de cosas en el que no imperen las relaciones depredativas entre individuos y colectivos.

Además de esto, creo que debe dejarse un espacio de juego para la noción de progreso en otros términos: al historiador le es legítimo interpretar y valorar (podríamos decir, reconstruir) a posteriori determinados decursos del pa-

22 Tal es la expresión que Lukács utilizó de manera autocrítica para referirse a su pensamiento de juventud; ver el Prólogo de Lukács a la segunda edición de su obra Historia y consciencia de clase, México, Grijalbo, 1969, pp. IX-XLI.

23 W. Benjamin, Libro de los Pasajes, ed. cit., p. 477.

24 F. Nietzsche, Humano, demasiado humano I, Madrid, Akal, 1997, §24, p. 57.

25 I. Kant, El conflicto de las facultades (ed. R. R. Aramayo), Madrid, Alianza Editorial, 2003, p. 154. 
sado como procesos en los que se ha producido un progreso en ciertos ámbitos de la vida, sin tener que suponer una lógica constitutiva del decurso histórico como tal o en su forma moderna. En este sentido considero válida, por ejemplo, la pretensión de reconstruir determinadas transformaciones acaecidas en el pasado en el plano político-moral como procesos de aprendizaje moral, sin que se tenga que dar aquí una hipostatización de ninguna lógica esencial a la historia ${ }^{26}$.

ad b) La actualización de la semilla liberadora de la Ilustración exige hacerse cargo del sufrimiento de las víctimas del pasado, avasalladas por una realidad que ha acabado imponiéndose como la única posible. Los proyectos y movimientos en los que puede rastrearse hoy una continuación del núcleo normativo de la Ilustración consiguen impulsar su crítica y su acción transformadora concibiéndolas en el marco de una peculiar constelación con proyectos análogos del pasado que fueron derrotados y con cuyo anhelo y pretensión de emancipación tratan de engarzar su propia actividad en el presente. El modo en que en el siglo XX importantes guerrillas latinoamericanas rescataron los nombres de Sandino, Farabundo Martí, Zapata, etc., muestra un modo de relación con el pasado, en concreto con la propia tradición (la tradición de los de abajo que no se dejan someter), que se ha tornado cada vez más relevante en un contexto en el que del pasado parece ir quedando sólo un bagaje de imágenes para los nostálgicos consumidores de la cultura de masas de otros tiempos y para los creadores de moda retro. La continuación del momento de verdad de la Ilustración exige, como pensó Benjamin en una situación en la que se dio también un estancamiento de la práctica crítica, una reconsideración del pasado como ámbito relevante para una relación moral que inerve el carácter transformador de la acción política en el presente ${ }^{27}$.

$a d \mathrm{c}$ ) Europa y Occidente ya no pueden aparecer como paradigma o reserva privilegiada de valores como la libertad, la democracia, la razón o la Ilustración. En este sentido, carece de sustento toda forma de eurocentrismo o etnocentrismo occidental. Esto constituye todo un clamor de nuestro tiempo. Si la Ilustración significa aún algo en este mundo de conflictos geopolíticos y religioso-culturales en que vivimos, debe devenir un proceso plural realizado en la confluencia de diferentes tradiciones culturales en diálogo intercultural donde ninguna, ni siquiera la de Europa, tiene la primacía ${ }^{28}$. El Horkheimer maduro consideró después de la Segunda Guerra Mundial que Occidente había dejado de ser (si alguna vez realmente lo fue) la fuente y el suelo propicio

26 Tanto Habermas como Honneth avanzan en esta dirección. Ver J. Habermas, La reconstrucción del materialismo histórico, Madrid, Taurus, 1981 y A. Honneth, La lucha por el reconocimiento, Barcelona, Crítica, 1997.

27 Sobre esto ver M. Löwy, Walter Benjamin. Aviso de incendio, Buenos Aires, FCE, 2002.

28 Ver R. Fornet-Betancourt, Transformación intercultural de la filosofía, Bilbao, Desclée de Brouwer, 2001. 
del interés por la emancipación ${ }^{29}$. Pues Occidente está ahora más preocupado por cuidar sus fronteras y mantener sus cotas de consumo. Horkheimer aducía que si nos acogemos a la imagen hegeliana de un papel históricamente privilegiado de determinados países y culturas en cada época a la hora de impulsar hacia delante la historia mundial, entonces puede sostenerse que Occidente ya no tiene ese papel, pues está interesado sólo en mantener el régimen de asimetrías global vigente, que le beneficia. El deseo y el interés por la transformación de lo existente y por el avance en la construcción de relaciones sociales e instituciones más justas se han ido desarrollando en cambio en nuevas tierras, y será sólo a partir de un diálogo entre las mismas que podrá articularse como fuerza histórica real. La existencia de exigencias reales en esta dirección palpables en el escenario social internacional quita todo carácter utópico (en el mal sentido de la palabra) a esta pretensión.

ad d) La vocación de la Ilustración de hacer del ser humano el señor y amo de la naturaleza ya no puede justificarse como evidente. Hoy el problema no es cómo dominar mejor a la naturaleza. El problema fundamental es cómo el proceso de apropiación de la naturaleza para efectuar el necesario metabolismo con ella con objeto de permitir la supervivencia de nuestra especie (relación metabólica de la que no podemos prescindir), puede conseguir que la naturaleza no sea simplemente expoliada y destruida y que los ecosistemas naturales que se conservan mantengan su existencia del modo menos dañado posible. Lo que se necesita es la introducción de un principio de prudencia respecto al otro dañado que es la naturaleza que nos circunda en nuestro castigado planeta, que se preocupe por proteger la integridad de un equilibrio ecológico que ya parece irreversiblemente dañado. Y ello exige necesariamente el cuestionamiento de un modelo de crecimiento desarrollista y consumista impulsado por la búsqueda de beneficio económico privado, también compartido por las formas aún vigentes de capitalismo estatal (denominado también como socialismo real). Plantear la cuestión ecológica significa problematizar modelos de desarrollo y de vida impulsados por una, a medias inconsciente, a medias criminal, ideología del progreso cuyos resultados catastróficos resultan a todas luces patentes.

$a d$ e) La forma burguesa de la Ilustración, su mantenimiento dentro de los límites definidos por las relaciones de propiedad burguesas, choca con los intentos de transformación del capitalismo en una dirección justa. Como ya apunté, la Ilustración histórica, con la excepción de Babeuf, no cuestionó la forma de propiedad privada burguesa. Pero en nuestros días sigue resultando patente que la privatización neoliberal de todas las fuentes de riqueza, servicios y bienes es una causa de perjuicios y no de beneficios para la inmensa mayoría. Por ello, este proceso de autoemancipación que es la Ilustración

29 Agradezco a Oliver Kozlarek esta indicación. Él usa el texto de Horkheimer en su artículo «Dos críticas de las "geografías imaginadas": Guillermo Bonfil Batalla y Roger Bartra», en Devenires. Revista de Filosofía y Filosofía de la cultura, Morelia, Facultad de Filosofía de la Universidad Michoacana, n. ${ }^{\circ}$ 15, 2007, p. 207. 
debe pensar otras formas de propiedad de los medios de producción, de los servicios y de los bienes además de la privada: como es el caso de la propiedad comunal, cooperativa, pública, ligada al uso o la gestión, etc. ${ }^{30}$ Como ha sostenido P. Anderson, «no hay ninguna inmutabilidad en el modelo tradicional de propiedad burguesa. Nuevas formas de propiedad popular deberán ser inventadas; formas que desarticulen la rígida concentración del poder que caracteriza a la empresa capitalista» ${ }^{31}$. Es decir, se trata de abrir el abanico de posibilidades a la hora de concebir formas diferentes de propiedad que rompan el monopolio que la propiedad privada burguesa posee en nuestro mundo social. Pero esto no debe implicar tratar de recuperar modelos de «socialismo» en los que el Estado acaba fusionando las figuras del padre y del (único) empresario. Y ello porque tal modelo clausura según unos parámetros restrictivos el proyecto de construcción histórica de lo nuevo, el cual debe alimentarse de la creatividad e iniciativa individual y colectiva. Y lo restringe en favor de una estructuración de la economía a partir de unos principios presuntamente incuestionables (en tanto que se derivan de unas escrituras tenidas por sagradas) que son incompatibles tanto con la adecuada satisfacción de las necesidades, que debería ser el objetivo de la actividad económica, como con la articulación democrática de la voluntad colectiva. Esto último me da pie a una última consideración sobre las tareas requeridas por una reilustración de la Ilustración.

ad f) La actualización de la Ilustración exige romper de raíz con toda forma de despotismo ilustrado, con el elitismo ligado al conocimiento o al mérito y con el paternalismo del gobernante respecto a un pueblo considerado como incapaz (todavía) de guiarse por su propio entendimiento. La Ilustración debe asumirse en cambio como un proceso de formación (Bildung) colectivo orientado a un fin que tiene que estar ya presente en cada uno de sus momentos: la constitución dentro de un marco democrático del sujeto capaz de decisión racional. La autonomía no tiene plazos y es intolerable efectuar una culpabilización de los individuos y colectivos, como en otro contexto hizo Kant, como responsables de la ausencia de condiciones para implementarla en un proyecto de vida común.

Sé que por el modo en que he planteado la problemática de la vigencia de la Ilustración, a pesar de mis prevenciones respecto de las críticas precipitadas, acabo poniéndome al alcance de una objeción que puede parecer contundente. Sostuvo Foucault casi al final de su vida que «es preciso rechazar todo cuanto se presente bajo la forma de una alternativa simplista y autoritaria: o se acepta la Aufklärung [Ilustración], y se permanece en la tradición de su ra-

30 Ver U. Duchrow y F. Hinkelammert, La vida o el capital. Alternativas a la dictadura global de la propiedad, San José de Costa Rica, DEI, 2003.

31 P. Anderson, «Más allá del neoliberalismo: lecciones para la izquierda», en E. Sader y P. Gentili (comps.), La trama del neoliberalismo. Mercado, crisis y exclusión social, La Habana, Editorial de Ciencias Sociales, 2003, p. 130. 
cionalismo (lo que para algunos se considera algo positivo y para otros, por el contrario, como un reproche), o se critica la Aufklärung y entonces se intenta escapar de estos principios de racionalidad (lo que una vez más puede ser tomado en buen o mal sentido). Y no se sale de este chantaje introduciendo matices "dialécticos" que busquen determinar lo que ha podido haber de bueno y de malo en la Aufklärung» ${ }^{32}$. Frente a tal objeción sólo me cabe asumir que mi aproximación a la cuestión de la Ilustración se ha inspirado en la noción hegeliana de refutación como modelo de crítica aplicada al debate teórico. Para Hegel, la refutación de una idea se debe derivar de esa misma idea, desarrollándose a partir de ella, «y no se monta desde fuera, mediante aseveraciones y ocurrencias contrapuestas» ${ }^{33}$. Efectivamente, lo que he tratado de exponer aquí es una crítica inmanente del concepto de Ilustración, que busca encontrar en el seno mismo de ese concepto la dimensión normativa que, como promesa no cumplida, posibilita cuestionar su plasmación histórica concreta realmente acontecida ${ }^{34}$. Asimismo he tratado de mostrar que el significado de la Ilustración para nosotros no es desligable del ámbito de expectativas sociopolíticas y conflictos sociales en que se generó el discurso ilustrado y ha definido la dirección de las apropiaciones, problematizaciones y actualizaciones del mismo en los dos últimos siglos. Ello no me ha impedido tratar de tematizar un momento de verdad de la Ilustración, pero siempre en el sentido de que tal momento se define en relación a las problemáticas y conflictos del presente.

Únicamente me queda puntualizar algo respecto a la objeción de Foucault respecto a ensayos de confrontación con el concepto de Ilustración como el que se esboza aquí. Mi aproximación a lo que define la Ilustración no apunta, como Foucault reprocha a los defensores de la misma, a una supuesta forma de racionalidad que la caracterizaría. Desde la perspectiva que se ha adoptado aquí, lo definitorio de ese movimiento hay que buscarlo en la dimensión político-moral. La importancia de remitir lo esencial de la Ilustración a tal dimensión es patente, en tanto que en ella se pone en juego el enfrentamiento práctico-político de los sujetos con una realidad que es la explícita negación de esa pretensión de autonomía individual y colectiva que, aun habiendo sido originada históricamente en el marco de un proceso que ha durado siglos y que ha carecido de toda teleología, reconocemos hoy como normativa respecto de lo que queremos ser.

32 M. Foucault, «¿Qué es Ilustración?», en op. cit., p. 345.

33 G. W. F. Hegel, Fenomenología del espiritu, México, FCE, 1966, pp. 18-9.

${ }^{34} \mathrm{Me}$ ha servido de orientación además la reflexión de Adorno sobre el concepto de progreso (caracterizada también por su «matiz» dialéctico) contenida en su artículo «Progreso», en Th. W. Adorno, Consignas, Buenos Aires, Amorrortu, 1973, pp. 28-46. 